\title{
Comparison between Full-timers and Part-timers of the Effect of Person-Organization Fit on Working Attitude: A Hypothesis-Generating Case Study Using Polynomial Regression Analysis with Response Surface Methodology
}

\author{
Norihiko Ogawa ${ }^{1}$, Daisuke Osato ${ }^{2}$, Kiyoshi Takahashi ${ }^{3}$ \\ Hosei University, Japan ${ }^{1}$ \\ Fukuoka Jo Gakuin Universiyt, Japan ${ }^{2}$ \\ Ritsumeikan University, Japan ${ }^{3}$
}

\begin{abstract}
The purpose of the present study is to compare the effects of Person-Organization fit on the organizational commitment of full-timers and part-timers using polynomial regression with surface response analysis, and to suggest an exploratory hypothesis based on this case study. A questionnaire survey was administered at a food retail/manufacturing company in Japan. After comparing the effects of $\mathrm{P}-\mathrm{O}$ fit on 129 full-timers and 567 part-timers in relation to their organizational commitment, we found that: (1) In the human-oriented vs. task-oriented dimension of organizational culture, whereas full-timers held certain levels of commitment when they fit their value and organizational culture (whether at high levels (human-oriented) or low levels (taskoriented) of congruence), part-timers increased their commitment only at low levels of congruence and tended to decrease commitment at high levels of fitness; (2) Although incongruence between individual value and organizational culture in two dimensions (human vs. task-oriented and autonomous vs. heteronomous) had a negative effect on commitment for both employment statuses, the directions of unfitness were different. While full-timers decreased their commitment more seriously when the value of organizational culture exceeded that of individual value, the opposite happened with part-timers, who showed more a serious decrease when the value of individual value exceeded that of organizational culture. Based on the results and partial inclusion theory, we suggest a new hypothesis that $\mathrm{P}-\mathrm{O}$ fit may have a relatively more serious effect on part-
\end{abstract}




\title{
International Conference on Research in HUMAN RESOURCE MANAGEMENT
}

\author{
March 7-9, 2019 , London-United Kingdom
}

timers than full-timers, and $\mathrm{P}-\mathrm{O}$ unfit may have a relatively more serious impact on full-timers than part-timers.

Keywords: employment status; organizational commitment; organizational culture, partial inclusion

theory; sense of values

Themes: P-O fit and employment status

\section{Introduction}

The purpose of the present study was to explore empirically the difference of the effect of personorganization fit (P-O fit) on employees' attitudes due to employment status. Concretely, how the congruence and the incongruence between individual value and organizational culture affect organizational commitment of the employees working in a food retail/manufacturing company and how the effect would be different between full-timers and part-timers, was examined using polynomial regression with response surface analysis. In addition, a new hypothesis could be suggested given the analysis of this case using the aforementioned methodology.

Response surface analysis is a method that helps in the understanding of relationship between a pair of two independent variables and the dependent variable by depicting the result of polynomial regression analysis within three-dimensional space (Shanok, et al., 2010). The method makes it possible to analyze the following three questions: 1 . How the congruence of two explanatory variables affect an outcome variable; 2 . How the incongruence of two explanatory variables affect an outcome variable; and 3. How the direction of the difference of two explanatory variables affect the outcome. The questions can be replaced in the context of $\mathrm{P}-\mathrm{O}$ fit research into how $\mathrm{P}-\mathrm{O}$ fit affects an outcome, how P-O unfit affects an outcome, and how the effects of P-O unfit directions (when person's value is bigger than the organizational value and vice versa) can be seen in the outcome. Although the traditional analysis of P-O fit which uses difference scores has considered fit and unfit as a coterminous phenomenon within a specific analytical dimension, response surface methodology can assist the understanding of each effect of unfit depending on the directions, as well as analyzing the effect of congruence and incongruence separately. Some exploratory new hypotheses concerning P-O fit might be expected to emerge from a case study using those methodological advantages.

\section{Review and Hypotheses}

\section{P-O fit reconsidered}

It is widely known that P-O fit has a positive effect on organizational commitment and job performance, and a negative effect on turnover and/or intention to quit (Hoffman \& Woehr, 2005; 


\title{
International Conference on Research in HUMAN RESOURCE MANAGEMENT
}

\author{
March 7-9, 2019 , London-United Kingdom
}

Verquer, Beehr, \& Wagner, 2003). Although such findings seem to be apparent, at least three issues on $\mathrm{P}-\mathrm{O}$ fit and the operationalization allow us to examine its effect.

The first issue is what the actual objects of "fitness" are. P-O fit is a subcategory of personenvironment (P-E) congruence defined compatibility existing between individuals and environments. The concept of P-E fit includes sub-concepts such as person-vocation fit, person-job fit, person-group fit, person-person fit, etc. This implies that organizations also have multiple sub-objects of congruence such as jobs, groups, administrators, and colleagues, as well as whole organizational characteristics such as goals, structures, and climates. Therefore, a first issue to be considered is what object in an organization should be assessed.

The second issue is what types of congruence should be used: supplementary fit, complementary fit, or both (Kristof, 1996). P-O fit was defined as "the compatibility between people and organizations that occurs when: (a) at least one entity provides what the other needs, or (b) they share similar fundamental characteristics, or (c) both (Kristof, 1996; pp.4-5)." The comprehensive definition of PO covering three types of fitness needs to choose the type of fitness.

The third issue also concerns the operationalization of the concept of fitness. Relatively simple assessment methods of fitness will be cognitive direct questions to respondents such as "Do you think the values of your organization match yours?" The congruence assessed by these types of questioning is called direct or subjective fitness (Kristof, 1996). In contrast, the assessing of the compatibility by comparing the replies from organizational agents such as managers with those from the members is indirect or objective fitness (op. cit.). The former has often been used because of its operability, however, it has tended to receive the criticism of common method biases. However, indirect/objective assessment has problems such as who can properly evaluate certain questions and how to convert the two predictors into a variable of congruence (e.g., difference scores or interaction terms). Based on the above, it is desirable to choose appropriate operationalization methods according to the phenomena to be studied while taking collectable data into account.

\section{Organizational culture as the object of fitness}

There are four domains of P-O fit between: (a) individual and organizational value, (b) individual and organizational goals, (c) individual preferences or needs and organizational structures or systems, and (d) individual character and organizational climate (Kristof, 1996).

Concerning the first issue of P-O fit, from the administrative standpoint, we focused on organizational characteristics rather than on individual ones, particularly organizational culture expected to be more stable than the goals, strategies, and structures. Organizational culture is generally defined as shared values among organizational members (Robbins \& Judge, 2007). Notwithstanding the insight by Schein (1985) that the essences of organizational culture are some "basic underlying assumptions" the members cannot recognize, the present study supposes the "espoused values" that can be discerned by organizational members as organizational culture due 


\title{
International Conference on Research in HUMAN RESOURCE MANAGEMENT
}

\author{
March 7-9, 2019 , London-United Kingdom
}

to their compatibility with empirical assessment. Although the way of recognizing organizational values varied among individual members, the possibility of sharing is opened via the meaning of exposed words being efficaciously communicated to/among/with other members.

Another well-known organizational characteristic that can be recognized is organizational climate. It is defined as a "set of characteristics that: (a) describe the organization and distinguish it from other organizations; (b) are relatively enduring over time; and (c) influence the behavior of people within an organization (Forehand \& Gilmer, 1964, p.362)." As was shown in the previous definition, organizational climate is a comprehensive concept and it can partially include organizational culture. Although both could be distinguished from each other conceptually, we propose organizational culture as "organizational values recognized by the members" because both concepts (1) need to be recognized by organizational members when they are assessed, (2) are relatively enduring characteristics of an organization, and (3) affect work attitudes of the members.

About the second issue of P-O fit regarding what specific types of congruence (supplementary fit, complimentary fit, and/or both) should be used, this study adopted supplementary fit which emphasize similarity between an organization and the individual. Because most of the members of our case study company was employed as part-timers, they were mainly expected to operate manufacturing and retailing routines and were not expected to have highly professional competences at least when they were employed. The recruiting situations of full-timers are similar to those of part-timers. Simultaneously, once a year, a large number of Japanese companies have been hiring new graduates in bulk, and such subjective selection criteria like "with whom do I want to work?" are prevailing (Ogawa \& Osato, 2013). As a result of such hiring practices, similar employees will be gathered in a company. Considering the above, supplementary value congruence which works as the base of smooth organizational communication was regarded as being adequate for the purposes of this study.

Here, organizational affective commitment was used as a dependent variable of P-O fit. It was defined as "the relative strength of an individual's identification with and involvement in a particular organization" (Mowday, Steers, \& Porter, 1979; p.226) and was regarded as a direct outcome of P-O fit. According to Mowday et al. (1979), it was characterized by at least the following three factors: “(1) a strong belief in and acceptance of the organization's goals and values; (2) a willingness to exert considerable effort on behalf of the organization; and (3) a strong desire to maintain membership in the organization" (op. cit., p. 226). These reflect positive work attitudes in a comprehensive manner, including acceptance of organizational values (culture) which in turn arouse work motivation and intention to participate fruitfully within the organization. Therefore, this leads to the following hypothesis concerning the relationship between $\mathrm{P}-\mathrm{O}$ fit and organizational commitment. 


\title{
International Conference on Research in HUMAN RESOURCE MANAGEMENT
}

\author{
March 7-9, 2019 , London-United Kingdom
}

Hypothesis1. Organizational commitment will be higher in proportion to congruence between organizational culture and individual values. (Conversely, organizational commitment will be lower in proportion to incongruence between organizational culture and individual values.)

\section{Job attitudes of full-timers and part-timers}

The number of non-regular employees in Japan, including part-timers has been increasing from 8.17 million people in 1989 to 20.36 million in 2017, and the ratio of non-regular workers among all labour force in Japan has also increased from under $20 \%$ in 1989 to $37.3 \%$ in 2017. Compared with the number of regular employees (34.23 million as of 2017), they have accounted for a considerable volume of the overall total.

Although research on relationships between employment types and job attitudes (including organizational commitment) have increased at the same time as relevantly associated social trends, the result of empirical studies of the differences or levels of job attitudes between regular workers and non-regular ones have varied (Thorsteinson, 2003).

However, as was suggested from the perspective of the partial inclusion theory (Miller \& Terborg, 1979), non-regular employees are considered to have relatively low organizational commitment compared with regular employees. Non-regular employees can work in plural organizations in contrast to regular ones (and who are basically prohibited side jobs and engaging in other companies, especially in Japan). Consequently, compared with regular employees, it is thought to be natural that non-regular employees have lower organizational commitment to a particular organization due to their partial involvement (cf., Matsuyama, 2003). Our empirical evidence using the same data sources of this case have shown also that the organizational commitment of full-timers was higher than that of the part-timers at the .001 statistically significance level (Ogawa, Osato, \& Tanaka, 2018). More prevailing and tangible data has also supported such conclusions. According to the Basic Survey on Wage Structure (Japanese Ministry of Health, Labour and Welfare, 2017), the average length of service of non-regular employees were 8.2 years, and it was comparatively shorter than that of regular employees which measured 12.8 years. Referring to the monthly total working hours to the Monthly Labour Survey of Dec.(JMHLW, 2018), 85.1 working hours of non-regular employees was about half the hours of regular employees(166.4hours). It was also reported by the Japanese Trade Union Confederation (JTUC) that the average of daily working hours of non-regular workers was 6.4 hours against 8.9 hours of regular workers (JTUC, 2015).

Those working styles of non-regular employees who have lower involvement in a specific labour organization against regular employees and partial inclusion theory suggest that influences from an organization would be slighter on part-timers than on regular full-timers. Value congruence to a specific organization might be a matter of indifference to part-timers who tend to have partial employment relationships with several organizations on the presupposition of a relatively limited period of employment, working hours, and tasks. In contrast, value congruence might well be more 


\title{
International Conference on Research in HUMAN RESOURCE MANAGEMENT
}

\author{
March 7-9, 2019 , London-United Kingdom
}

serious for attitude formation of full-timers who have a longer employment relationship with a specific organization and who are expected to work longer hours for various advanced tasks.

When the hypothesis about difference of the congruence effect according to employment status was built, the effect of P-O fit and P-O unfit was supposed to be the same because of the results of the prevailing $\mathrm{P}-\mathrm{O}$ fit studies that consider fit and unfit as single dimension.

Hypothesis 2. The effect of P-O fit and P-O unfit on organizational commitment of full-timers will be larger than that of part-timers.

Although the second hypothesis was built on the assumption that fit and unfit should be opposite poles of one dimension, the third hypothesis about the effect of directions of incongruence might be useful for further understanding of this field as well enable us to take methodological advantage of the response surface analysis. What kind of difference will there be in an effect between the P-O unfit calculated in the case where the values of organizational culture are larger than the pairing values of the personal sense of value and the P-O unfit calculated in the case where the values of organizational culture are smaller than the pairing values of the personal sense of value?

It seems that Japanese full-timers, who are under long-term employment practices, expect congruence with an organization when they decided to work in that particular organization. Ogawa \& Osato (2011) explored the criteria of Japanese college students in choosing a company they would work for, and found that subjective anticipatory fittedness to organizational climates functioned as a criterion for choosing a company. After working in a company, newcomers will start to internalize a particular organizational culture through organizational socialization processes, including induction trainings. According to the ASA model (Attraction, Selection, and Attrition framework; Schneider, 1987), people who have interests and values similar to an organization are attracted by, and, thus, apply to the organization. Thereby the organization selects more congruent people from among the general application pool. Furthermore, even after working within a particular organization, the selected people who are not good fit with the organization are nonetheless worn down. Consequently, it is thought that employees congruent with the organization are established as the "permanent" members as it were. Therefore, it is supposed that full-timers made a decision to participate in, and to continue working for, their organizations on the premise of a value fit between them and the organizations.

Part-timers will also be influenced more or less by such socializing effects after beginning to work for a company. However, the company's employment selection criteria are generally not strict relative to those of full-timers because of their shorter, more limited period of employment. Part-timers themselves also tend to decide to work for an organization more casually, on the basis of the working conditions being convenient for them i.e. hourly pay, working hours, working place, or duties etc. It is supposed that part-timers will choose to engage in partial working with an organization 


\title{
International Conference on Research in HUMAN RESOURCE MANAGEMENT
}

\author{
March 7-9, 2019 , London-United Kingdom
}

temporarily in preference to their own conveniences rather than full participation required loyalty toward that particular organization. Broadly speaking, with a resigned acceptance of the criticism of immoderate simplicity, it might be possible to say that full-timers have the tendency to work for an organization with adjusting their own values to the organizational culture, and that part-timers have the tendency to work for an organization with adjusting the working conditions presented by the organization to themselves at their own convenience.

With the above considerations in mind, full-timers might feel a distance from their organizations by becoming aware at a later time of joining that they cannot adjust to its organizational values or cannot satisfy organizational requirements despite their pre-joining expectations. Conversely, parttimers will be motivated to work in a more limited fashion with (and to maintain a distance from) their organizations by recognizing that the organizational values might not be compatible with theirs or cannot satisfy their personal requirements. Although other hypotheses could be built taking individual diversities into account, the third hypothesis about the directions of P-O unfitness was presented for the convenience of allowing us to advance our explorative study. Namely:

Hypothesis 3. Organizational commitment of full-timers will be lower in the case that incongruence generated from individual values fall short of corresponding organizational values (that is, organizational culture which an organization requires its members to believe) than the commitment in the case of incongruence generated from individual values differing excessively from corresponding organizational values (culture). In sum, organizational commitment of full-timers will be lower in the case of the value unfit from $\mathrm{O}>\mathrm{P}$ than the value unfit from $\mathrm{O}<\mathrm{P}$.

Inversely, organizational commitment of part-timers will be lower in the case that incongruence generated from individual values deviate excessively from the corresponding organizational values (culture) than the commitment in the case of incongruence generated from individual the values falling short of corresponding organizational values. In short, the organizational commitment of parttimers will be lower in the case of the value unfit from $\mathrm{O}<\mathrm{P}$ than the value unfit from $\mathrm{O}>\mathrm{P}$.

\section{Methods}

\section{Survey outline}

A questionnaire survey titled "The survey on attitudes in the workplace" was administered online for 17 days from November 1st to 17th in 2017. The subjects were 1,138 employees working for a food retail/manufacturing company in Japan.

The response rate was $54.2 \%$ and 700 respondents were provided. The $84.1 \%$ (589 respondents) answered through smart-phone and the others by PC (15.4\%, 108 respondents) or by cellular phone (4\%, three respondents). 


\title{
International Conference on Research in HUMAN RESOURCE MANAGEMENT
}

\author{
March 7-9, 2019 , London-United Kingdom
}

\section{The case company and the correspondents}

The food retail/manufacturing company was founded around 70 years ago. The headquarters is located in Kansai area, west region of Japan. It has been extensively running chain stores specialized in some ready-to-eat foods using particular foodstuffs. The number of stores amount to more than 100 in Japan and some are located outside the country as at November 2017. Sales reached to six billion yen (almost $\$ 55$ million USD at an exchange rate of 110 yen to the dollar) and the number of employees was more than 1,000 at that time. The subject of the present study concerned only employees working within Japan.

The age of the respondents ranged from 15 to 72 years and the average was 27.9 years old (sd. 11.7). The average length of service in the company was a little less than three years (35.6 months, sd.51.5) and there were employees who had literally just started the job as well who had worked with the company for up to 37 years. Some of these long serving employees even being found among the part-timers.

The respondents were composed of 515 females (73.6\%) and 185 males (26.4\%). Most of their employment status was part-time constituting $81.0 \%$ (or 567 employees); the others were fulltimers. Regarding their academic backgrounds, high-school graduates accounted for the majority (accounting $48.1 \%$ ), followed by college graduates who constituted $24.1 \%$. The overall percentage of married employees was $75.8 \%$.

\section{Measures}

The scale of Ogawa, Takahashi, \& Osato (2014) was modified to assess organizational culture and individual value. It was composed of the following seven dimensions: (1) collectivistic vs. individualistic, (2) human-oriented vs. task-oriented, (3) autonomy vs. heteronomy, (4) logical vs. intuitive, (5) innovative vs. conservative, (6) process-oriented vs. result-oriented, and (7) long-rangeoriented vs. short-range-oriented.

(1) Collectivistic vs. individualistic referred to whether the organization emphasized organizational (or group) objectives, or personal thoughts and interests. (2) Human-oriented vs. task-oriented referred to whether the organization emphasized economic rationality, or instead attached greater importance to consideration of its members' individual opinions in decision-making. (3) Autonomy vs. heteronomy referred to whether the organization encouraged the members to act based on their own ideas or faithfully abide by rules and orders. (4) Logical vs. intuitive referred to whether the organization considered logic and scientific attitudes or feeling and intuition to be critical in problem solving. (5) Innovative vs. conservative referred to whether conventional customs and traditions were regarded as important, or whether high value was placed on change. (6) Process-oriented vs. result-oriented referred to whether the organizational members tended to value aspects of the process leading to a result, such as input effort and adequacy of procedures and methods, or only the result. (7) Long-range-oriented vs. short-range-oriented was concerned with whether the value 


\title{
International Conference on Research in HUMAN RESOURCE MANAGEMENT
}

\author{
March 7-9, 2019 , London-United Kingdom
}

of something was accepted even when a result was not immediate and tackling that thing was encouraged, or only immediate results were appreciated.

The respondents were asked separately about both the degree of fittedness with their company concerning the seven dimensional values and the degree of their own sympathy with these seven values. In other words, the indirect P-O fit assessment was adopted to use the methodology of polynomial regression with response surface analysis that needs to input two pairing independent variables of organizational culture and individual value into a regression.

To assess the organizational culture, the direction of "How much do you think are the following sentences true to your companies' policies?" was presented and allowed the respondents to answer by 5-point Likert-typed scales anchored from 1 with "not true" to 5 with "true." For the assessment of their own personal value, the direction of "How much do you feel sympathy to the following sentences?" was similarly presented, and 5-point scales anchored from 1 with "not much" to 5 with "much" were used.

Referring to the results of factor analyses, seven composite variables of organizational culture and those of personal value were obtained with the coefficients of reliability (Cronbach's alfa) ranged from .65 to .86 concerning organizational culture and those from .65 to .80 concerning personal values. The results suggested the variables should be available for further analyses.

Organizational commitment was assessed by four items extracted from Allen \& Meyer (1990) of the affective commitment dimension. The 5-point scale was adopted and the coefficient of alfa showing .86 was regarded as a sufficiently high level.

\section{Results}

\section{The results of polynomial regression analysis}

To examine the effect of $\mathrm{P}-\mathrm{O}$ fit and $\mathrm{P}-\mathrm{O}$ unfit on organizational commitment, the polynomial regression analyses were carried out along with the following procedures. First, the number of samples belonging to each status (full-timers or part-timers) and the component ratios were calculated in order to confirm whether there were a certain number of sample employees showing satisfactory differences between two corresponding variables (organizational culture and personal value) for each of seven dimensions (table 4.1). According to the results showed on the table, the group of employees whose values were congruent with the organizational culture (the categories showing the values of organizational culture were nearly equal to those of personal value) constituted around half of the whole in all the seven dimensions and in both of employment statuses. This suggested that employees congruent with organizational culture were the majority in the organization. In addition, the fact that there were around $20 \%$ of people in all the categories of combinations of seven dimensions with both groups of full-timers and part-timers suggested that response surface analysis would be useful in this case. 


\section{International Conference on Research in HUMAN RESOURCE MANAGEMENT}

March 7-9, 2019 , London- United Kingdom

Table 4.1: The component ratios by employment statuses

\begin{tabular}{|c|c|c|c|c|}
\hline Dime & $\begin{array}{l}\text { Full-timers } \\
\text { Groups }\end{array}$ & $n$ & $\begin{array}{l}\text { Part-timers } \\
\text { Groups ratio }\end{array}$ & $\mathrm{n}$ \\
\hline $\begin{array}{l}\text { Collectivistic } \\
\text { vs. } \\
\text { individualistic, }\end{array}$ & $\begin{array}{l}\text { Org.> Person } \\
34 \\
\text { Org. } \fallingdotseq \text { Person } \\
58 \\
\text { Org.<Person } \\
37 \\
\text { Sum } \quad 100.0 \%\end{array}$ & $\begin{array}{l}26.4 \% \\
45.0 \%\end{array}$ & $\begin{array}{l}\text { Org.> Person } \\
160 \\
\text { Org. }=\text { Person } \\
270 \\
\text { Org.<Person } \\
137 \\
\text { Sum } \quad 100.0 \%\end{array}$ & $\begin{array}{l}24.2 \% \\
567\end{array}$ \\
\hline $\begin{array}{l}\text { Human-oriented } \\
\text { vs. } \\
\text { task-oriented, }\end{array}$ & $\begin{array}{l}\text { Org.> Person } \\
30 \\
\text { Org. } \fallingdotseq \text { Person } \\
65 \\
\text { Org.<Person } \\
34 \\
\text { Sum } \quad 100.0 \%\end{array}$ & $\begin{array}{l}23.3 \% \\
50.4 \% \\
26.4 \% \\
129\end{array}$ & $\begin{array}{l}\text { Org.> Person } \\
113 \\
\text { Org. } \fallingdotseq \text { Person } \\
333 \\
\text { Org.<Person } \\
121 \\
\text { Sum } \quad 100.0 \%\end{array}$ & $\begin{array}{l}19.9 \% \\
58.7 \% \\
21.3 \% \\
567\end{array}$ \\
\hline $\begin{array}{l}\text { Autonomy } \\
\text { vs. } \\
\text { heteronomy, }\end{array}$ & $\begin{array}{l}\text { Org.> Person } \\
36 \\
\text { Org=Person } \\
58 \\
\text { Org.<Person } \\
35 \\
\text { Sum } \quad 100.0 \%\end{array}$ & $\begin{array}{l}27.9 \% \\
45.0 \% \\
27.1 \% \\
129\end{array}$ & $\begin{array}{l}\text { Org.> Person } \\
146 \\
\text { Org. } \fallingdotseq \text { Person } \\
291 \\
\text { Org.<Person } \\
130 \\
\text { Sum } \quad 100 .\end{array}$ & $\begin{array}{l}25.7 \% \\
51.3 \% \\
22.9 \% \\
567\end{array}$ \\
\hline $\begin{array}{l}\text { Logical } \\
\text { vs. } \\
\text { intuitive }\end{array}$ & $\begin{array}{l}\text { Org.> Person } \\
28 \\
\text { Org.ĐPerson } \\
66 \\
\text { Org.<Person } \\
35 \\
\text { Sum } \quad 100.0 \%\end{array}$ & $\begin{array}{l}21.7 \% \\
51.2 \% \\
27.1 \% \\
129\end{array}$ & $\begin{array}{l}\text { Org.> Person } \\
99 \\
\text { Org.`Person } \\
318 \\
\text { Org.<Person } \\
150 \\
\text { Sum } \quad 100.0 \%\end{array}$ & $\begin{array}{r}17.5 \% \\
56.1 \% \\
26.5 \% \\
567\end{array}$ \\
\hline $\begin{array}{l}\text { Innovative } \\
\text { vs. } \\
\text { conservative }\end{array}$ & $\begin{array}{l}\text { Org.> Person } \\
25 \\
\text { Org. }=\text { Person } \\
77\end{array}$ & $\begin{array}{l}19.4 \% \\
59.7 \%\end{array}$ & $\begin{array}{l}\text { Org.> Person } \\
131 \\
\text { Org. ĐPerson } \\
325\end{array}$ & $\begin{array}{l}23.1 \% \\
57.3 \%\end{array}$ \\
\hline
\end{tabular}




\title{
International Conference on Research in HUMAN RESOURCE MANAGEMENT
}

\author{
March 7-9, 2019 , London-United Kingdom
}

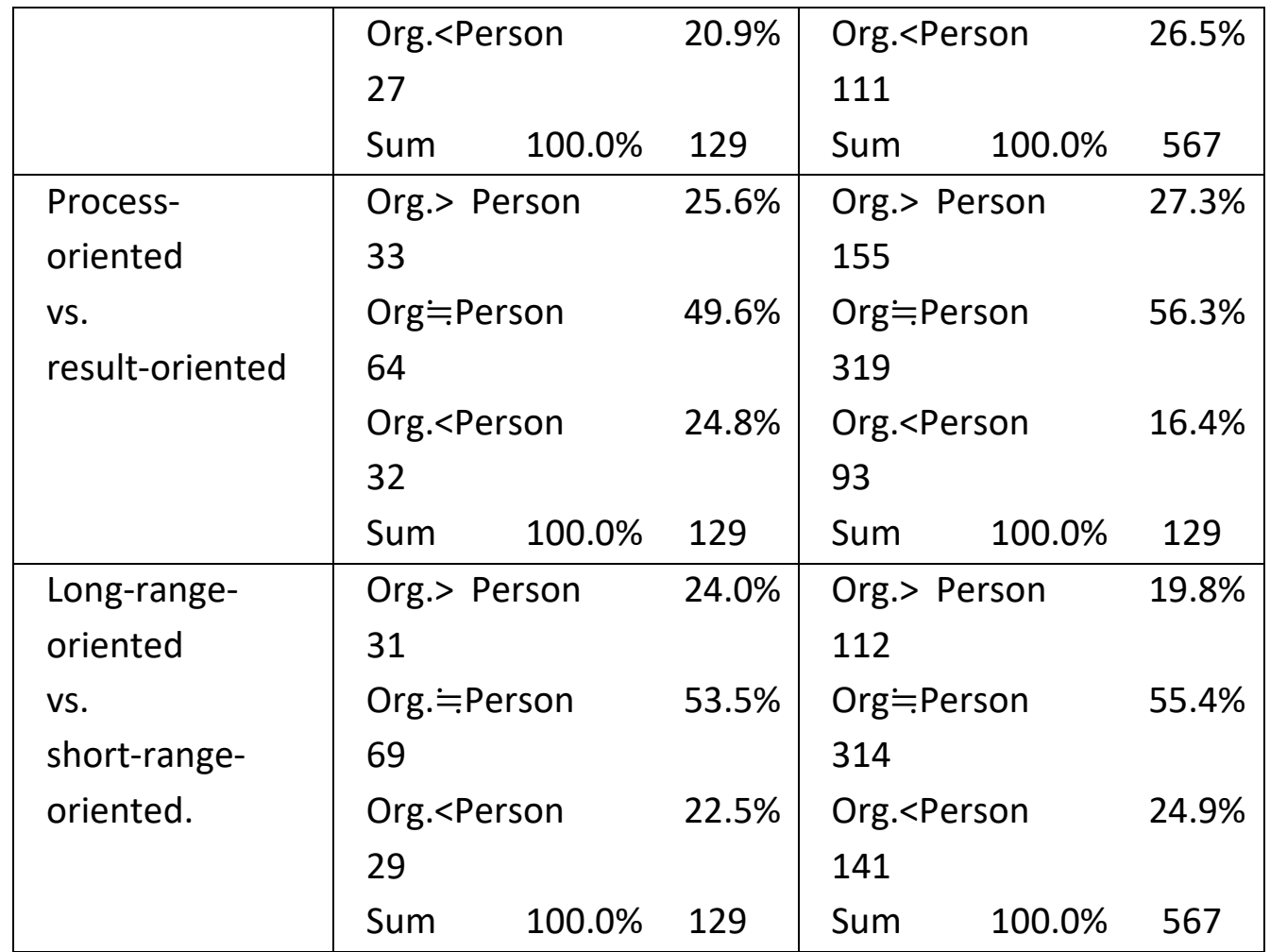

Next to the above preliminary analyses, each square of seven organizational culture variables centered by median $(=3)$ of the measure, and interactions of each of the seven dimensional centered variable pertaining to organizational culture and corresponding centered variables of seven personal values, and each square of seven personal value variables centered alike were regressed onto organizational commitment for each dimension and with both employment statuses separately ${ }^{1}$.

Regarding the results, although the regressions for part-timers were significant at all the seven dimensions, those for full-timers were significant only at two dimensions of the human-oriented vs. task-oriented and the autonomy vs. heteronomy (Table 4.2). To compare with the effect of P-O fit/unfit between full-timers and part-timers on commitment, further analyses were performed concerning the two dimensions showing statistical significance of coefficient of determination in both employment statuses.

\footnotetext{
${ }^{1}$ When the general formula of polynomial regression is " $\mathrm{Z}=\mathrm{b}_{0}+\mathrm{b}_{1} \mathrm{X}+\mathrm{b}_{2} \mathrm{Y}+\mathrm{b}_{3} \mathrm{X}^{2}+\mathrm{b}_{4} \mathrm{XY}+\mathrm{b}_{5} \mathrm{Y}^{2}+\mathrm{e}$," an example of the analysis was presented as following: Organizational commitment $=b_{0}+b_{1}$ (organizational culture of collectivistic vs. individualistic) $+b_{2}$ (personal value of collectivistic vs. individualistic) $+b_{3}$ (organizational culture of collectivistic vs. individualistic $)^{2}+\mathrm{b}_{4}$ (organizational culture of collectivistic vs. individualistic)(personal value of collectivistic vs. individualistic) $+\mathrm{b}_{5}$ (personal value of collectivistic vs. individualistic $)^{2}+\mathrm{e}$
} 


\section{International Conference on Research in HUMAN RESOURCE MANAGEMENT}

\section{March 7-9, 2019 , London-United Kingdom}

Table 4.2: The results of Polynomial regressions of 7 dimensions

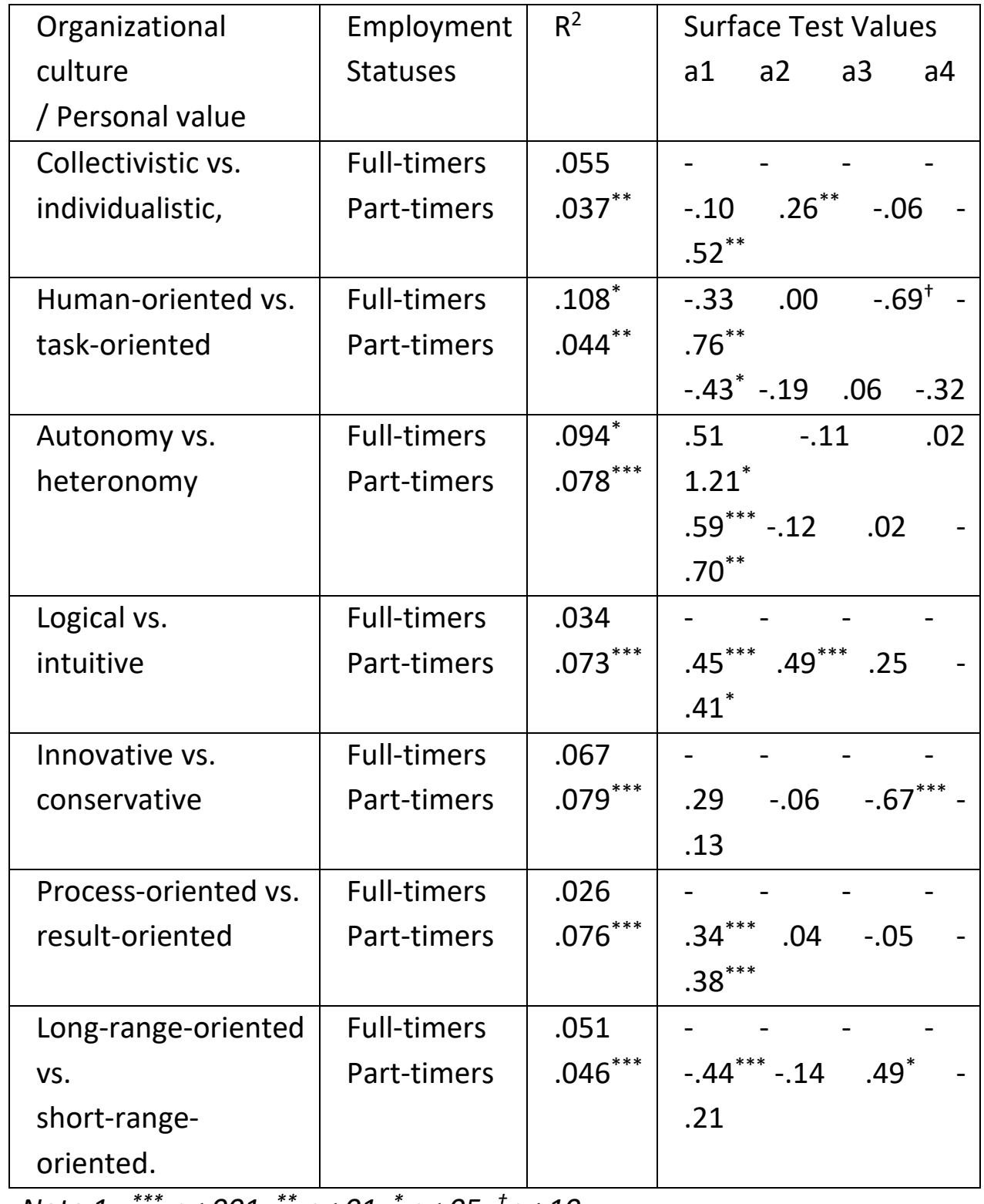

Note 1: ${ }^{* * *} p<.001,{ }^{* *} p<.01,{ }^{*} p<.05,{ }^{+} p<.10$

Note 2: Full-timers $n=129$, Part-timers $n=567$

\section{The results of surface response analyses}

To compare the effect of $\mathrm{P}-\mathrm{O}$ fit and unfit on organizational commitment between full-timers and part-timers, surface response analyses were performed based on the results of the two polynomial regressions with statistical significance. 


\title{
International Conference on Research in HUMAN RESOURCE MANAGEMENT
}

\author{
March 7-9, 2019 , London-United Kingdom
}

The result of the polynomial regression analysis to examine each effect of $\mathrm{P}-\mathrm{O}$ fit/unfit in the humanoriented vs. task-oriented dimension on organizational commitment for full-timers and part-timers was shown in detail (Table 4.3).

(1) The result of the response surface analysis on human-oriented vs. task-oriented dimension for fulltimers

The tendency was observed in full-timers that the higher congruent at the low standard between the organizational culture and the personal value of human-oriented vs. task-oriented dimension was, the higher organizational commitment was. In other words, organizational commitment of fulltimers became higher when organizational culture and personal value fit at the high level of the taskoriented view (Figure 4.1).

When the congruence was observed at the high level of the human-oriented variable on the other hand, organizational commitment of full-timers was lower than that of at the high level of the taskoriented variable. However, the value of organizational commitment did not fall under the median of 3 as with the case of unfitness referred to afterwards. Those findings could also be pointed out from the results of the surface value tests. The value of $a_{2}(.00)$ suggested that the perfect line of congruence (the line of $X=Y$, at the bottom of Figure 4.1) and organizational commitment (Z-axis of the figure) had a linear relationship. In addition, the slope of the perfect congruence line along the Z-axis of organizational commitment represented as the $a_{1}$ value $(-.33)$ was negative and with no significance. These results should indicate that the level of organizational commitment was almost the same in the case of congruence both even at the high level (representing human-oriented) and even at the low level (representing task-oriented).

However, when the incongruence between organizational culture and personal value on the human-oriented vs. task-oriented dimension was observed, organizational commitment dropped significantly. That was also shown by the $a_{4}$ value $(-.70)$ of curvature at $1 \%$ level of significance representing non-linear relationship of convexity between the line of incongruence (the broken line of $X=-Y$ in the figure) and $Z$-axis of organizational commitment.

Regarding the directions of incongruence, organizational commitment of the full-timers who were observed incongruence resulting from the combinations of high human-oriented personal values and low human-oriented organizational culture was lower than those full-timers who had the incongruence from the opposite combinations of low human-oriented personal values and high human-oriented organizational culture. The result was also found by the significance of the $a_{3}$ value $(-.69)$ at a level of .10. The difference of the effect level of incongruence could be suggested depending on the directions of incongruences.

Concerning to the full-timers, results of the surface response analyses on the human-oriented vs. task-oriented dimension could be summarized into the following three points: (a) Organizational commitment of the full-timers was maintained at a certain level of high when the personal values 


\title{
International Conference on Research in HUMAN RESOURCE MANAGEMENT
}

\author{
March 7-9, 2019 , London-United Kingdom
}

and the organizational culture were matched both at high level (human-oriented) and at low level (task-oriented), (b) Conversely, the commitment fell down considerably if there was an incongruence between the personal values and organizational culture, and (c) The decline in organizational commitment was observed especially in the case of incongruence generating from the combinations of high personal values and low organizational culture (i.e., $\mathrm{P}>\mathrm{O}$ unfit).

(2) The results of the response surface analysis on human-oriented vs. task-oriented dimension for part-timers

Similar result were also found in the case of part-timers in that organizational commitment become higher when the personal values and organizational culture matched on the human-oriented vs. task-oriented dimension at the low level, i.e., when both values approached to task-oriented pole (Figure 4.2). In contrast to full-timers, the tendency was apparently observed in part-timers that organizational commitment deteriorated when the personal value and organizational culture matched on the human-oriented vs. task-oriented dimension at the high level of human-oriented. The findings were also supported by the linear relationship between Z-axis of organizational commitment and the perfect line that revealed from the $a_{2}$ value (-.19) showing no significance, as well as the result that the $a_{1}$ value $(-.43)$ representing the slope indicated negative significance at the level of $5 \%$.

Task-oriented culture might reflect the rational standardization of the work operations prevailing at the operation sites of manufacturing and retailing that the part-timers mainly engaged in. It might be difficult for the part-timers incongruent with task-oriented main culture of manufacturing /retailing fields to have a sense of belongingness to the organization.

It was also found that, when there was incongruence between personal values and organizational culture on the human-oriented vs. task-oriented dimension, organizational commitment of parttimers declined in the same way as full-timers.

However, the directions of incongruence might work differently than with full-timers. Namely, the organizational commitment of the part-timers who had the incongruence resulting from combinations of high human-oriented organizational culture and low human-oriented personal values was slightly lower than that of the part-timers with the incongruence generated by combinations of low human-oriented organizational culture and high human-oriented personal value, provided the tendency was not supported by statistical significance because the value of $a_{3}$ (.06) that represented the slope between the line of incongruence and $Z$-axis as well as the $a_{4}$ value (-.32) of curvature were not significant.

Table 4.3: The results of polynomial regressions on organizational commitment concerning humanoriented vs. task-oriented dimension and the surface tests 


\section{International Conference on Research in HUMAN RESOURCE MANAGEMENT}

March 7-9, 2019 , London- United Kingdom

\begin{tabular}{|c|c|c|c|c|}
\hline \multirow{2}{*}{ Organizational commitment } & \multicolumn{2}{|c|}{ Full-timers } & \multicolumn{2}{|c|}{ Part-timers } \\
\hline & $\mathrm{b}$ & se & $\mathrm{b}$ & $\mathrm{se}$ \\
\hline Constant & $3.65^{* * *}$ & 0.14 & $3.12^{* * *}$ & 0.08 \\
\hline Personal value $(\mathrm{PV})$ in $\mathrm{H}$. vs. T & $-0.31+$ & 0.16 & -0.11 & 0.10 \\
\hline Organizational culture(OC) in H. vs. T. & 0.11 & 0.14 & $-0.15^{+}$ & 0.09 \\
\hline Square of PV in H. vs. T & $-0.30^{+}$ & 0.15 & -0.15 & 0.11 \\
\hline Interaction of the PV and the $\mathrm{OC}$ & $0.38 *$ & 0.16 & 0.06 & 0.11 \\
\hline Square of OC in H. vs. T. & -0.08 & 0.09 & -0.10 & 0.07 \\
\hline $\mathrm{R}^{2}$ & 0.11 & & 0.04 & \\
\hline \multicolumn{5}{|l|}{ Surface tests } \\
\hline$a_{1}$ & \multicolumn{2}{|l|}{-0.33} & \multicolumn{2}{|c|}{$-0.43^{*}$} \\
\hline$a_{2}$ & \multicolumn{2}{|l|}{0.00} & \multicolumn{2}{|c|}{-0.19} \\
\hline$a_{3}$ & \multicolumn{2}{|l|}{$-0.69+$} & \multicolumn{2}{|l|}{0.06} \\
\hline $\mathrm{a}_{4}$ & \multicolumn{2}{|c|}{$-0.70 * *$} & \multicolumn{2}{|c|}{-0.32} \\
\hline
\end{tabular}

Note $1,{ }^{* * *} p<.001,{ }^{* *} p<.01,{ }^{*} p<.05,{ }^{+} p<.10$

Note $2, \mathrm{n}$ of full-timers $=129, \mathrm{n}$ of part-times $=567$

Figure 4.1: Response surface analysis for full-timers on the human-oriented vs. task-oriented dimension

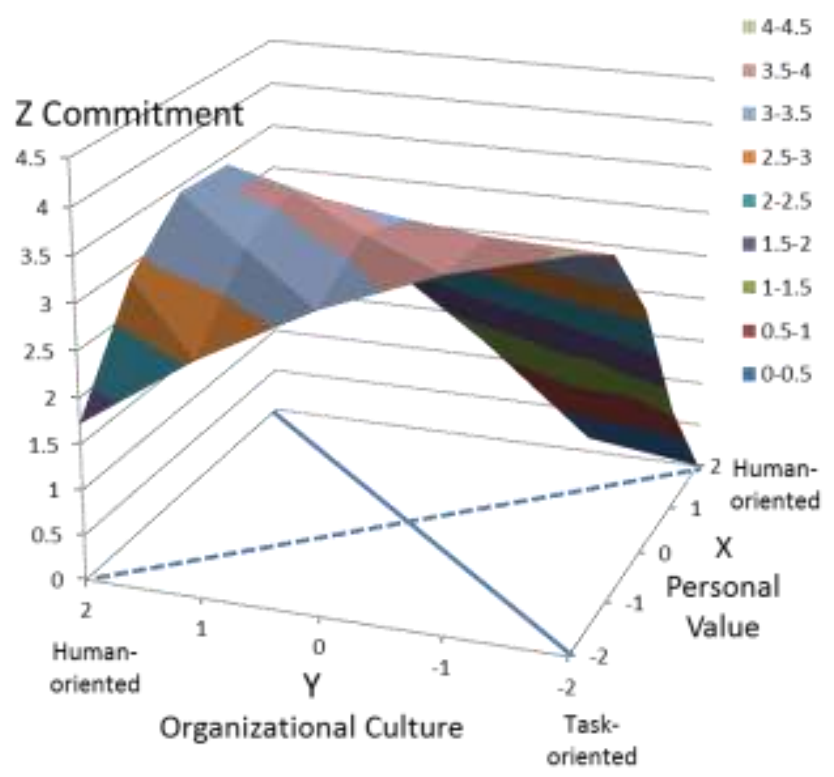

Figure 4.2: Response surface analysis for part-timers on the human-oriented vs. task-oriented dimension 


\section{International Conference on Research in HUMAN RESOURCE MANAGEMENT}

\section{March 7-9, 2019 , London- United Kingdom}

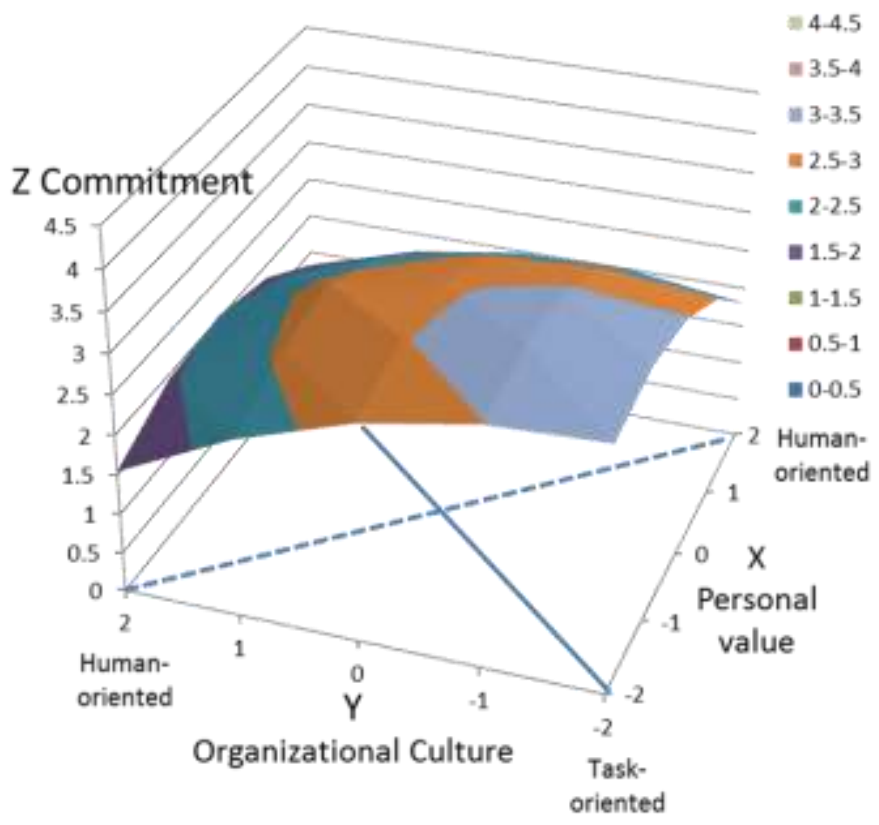

\subsection{Dimension of autonomy vs. heteronomy,}

The results of the polynomial regression analyses (Table 4.4) with the surface response analyses (Figure 4.3) to examine the effect of $\mathrm{P}-\mathrm{O}$ fit/unfit in the autonomy vs. heteronomy dimension on organizational commitment for full-timers and part-timers is shown.

As Figure 4.3 shows, the levels of organizational commitment of both full-timers and part-timers were high when the congruence between the organizational culture and the personal value on the dimension of autonomy vs. heteronomy was observed at the high levels of the heteronomy. Although there was a linear relationship between the Z-axis and the perfect line of congruence shown by the $a_{2}$ value of no significance, the significance of the slope along the Z-axis was found only in part-timers $\left(a_{3}=.58\right.$, at $0.1 \%$ level), not in full-timers $\left(a_{3}=.51, n . s\right.$. $)$ provided the both values of $a_{3}$ were at the comparable level.

Therefore, as for the part-timers, the level of organizational commitment was higher in the case of $\mathrm{P}-\mathrm{O}$ fit at high levels heteronomy than in the case of P-O fit at low levels of heteronomy $(=\mathrm{P}-\mathrm{O}$ fit at high levels of autonomy). On the other hand, concerning full-timers, organizational commitment should be regarded as almost being at the same level between the P-O fit at high heteronomy and the $\mathrm{P}-\mathrm{O}$ fit at low heteronomy. Those results might indicate that heteronomous culture had been prevailed in the company, especially among part-timers. The part-timers might work on the site of retailing and manufacturing where the rules and manuals to follow were developed to extend the chain stores.

On the other hand, organizational commitment of full-timers and part-timers also declined when there was the incongruence between the organizational culture and the personal value on the 


\section{International Conference on Research in HUMAN RESOURCE MANAGEMENT}

March 7-9, 2019 , London-United Kingdom

autonomy vs. heteronomy dimension. Differences in the effect created by incongruent directions was not found in this dimension because both the $a_{4}$ values of full-timers and part-timers representing the curvatures of the lines of incongruence indicated negative significance. Likewise, no different effect depending on the directions of incongruence was pointed out because the $a_{3}$ values which represented the slopes of incongruent lines against Z-axis were not significant.

Table 4.4: The results of polynomial regressions on organizational commitment concerning autonomy vs. heteronomy dimension and the surface tests

\begin{tabular}{|c|c|c|c|c|}
\hline \multirow{2}{*}{ Organizational commitment } & \multicolumn{2}{|c|}{ Full-timers } & \multicolumn{2}{|c|}{ Part-timers } \\
\hline & $\mathrm{b}$ & se & $\mathrm{b}$ & se \\
\hline Constant & $3.64^{* * *}$ & 0.17 & $3.13^{* * *}$ & 0.09 \\
\hline Personal value $(\mathrm{PV})$ in $\mathrm{A}$. vs. $\mathrm{H}$ & 0.17 & 0.17 & $0.19^{+}$ & 0.10 \\
\hline Organizational culture $(\mathrm{OC})$ in A. vs. $\mathrm{H}$. & 0.16 & 0.20 & $0.19^{+}$ & 0.11 \\
\hline Square of PV in A. vs. H. & -0.24 & 0.23 & -0.11 & 0.12 \\
\hline Interaction of the $\mathrm{PV}$ and the $\mathrm{OC}$ & $0.55^{+}$ & 0.29 & $0.29^{*}$ & 0.15 \\
\hline Square of OC in A. vs. H. & $-0.42 *$ & 0.19 & $-0.30^{* *}$ & 0.11 \\
\hline $\mathrm{R}^{2}$ & \multicolumn{2}{|c|}{$0.09 *$} & \multicolumn{2}{|c|}{$0.08 * *$} \\
\hline \multicolumn{5}{|l|}{ Surface tests } \\
\hline$a_{1}$ & \multicolumn{2}{|l|}{0.51} & \multicolumn{2}{|c|}{$0.59 * * *$} \\
\hline$a_{2}$ & \multicolumn{2}{|l|}{-0.11} & \multicolumn{2}{|c|}{-0.12} \\
\hline$a_{3}$ & \multicolumn{2}{|l|}{0.02} & \multicolumn{2}{|l|}{0.02} \\
\hline$a_{4}$ & \multicolumn{2}{|l|}{$-1.21 *$} & \multicolumn{2}{|c|}{$-.007 * *$} \\
\hline
\end{tabular}

Note $1,{ }^{* * *} p<.001,{ }^{* *} p<.01,{ }^{*} p<.05,{ }^{+} p<.10$

Note $2, \mathrm{n}$ of full-timers $=129, \mathrm{n}$ of part-times $=567$

Figure 4.3: Response surface analysis on autonomy vs. heteronomy dimension for full-timers and part-timers 


\section{International Conference on Research in HUMAN RESOURCE MANAGEMENT}

\section{March 7-9, 2019 , London- United Kingdom}
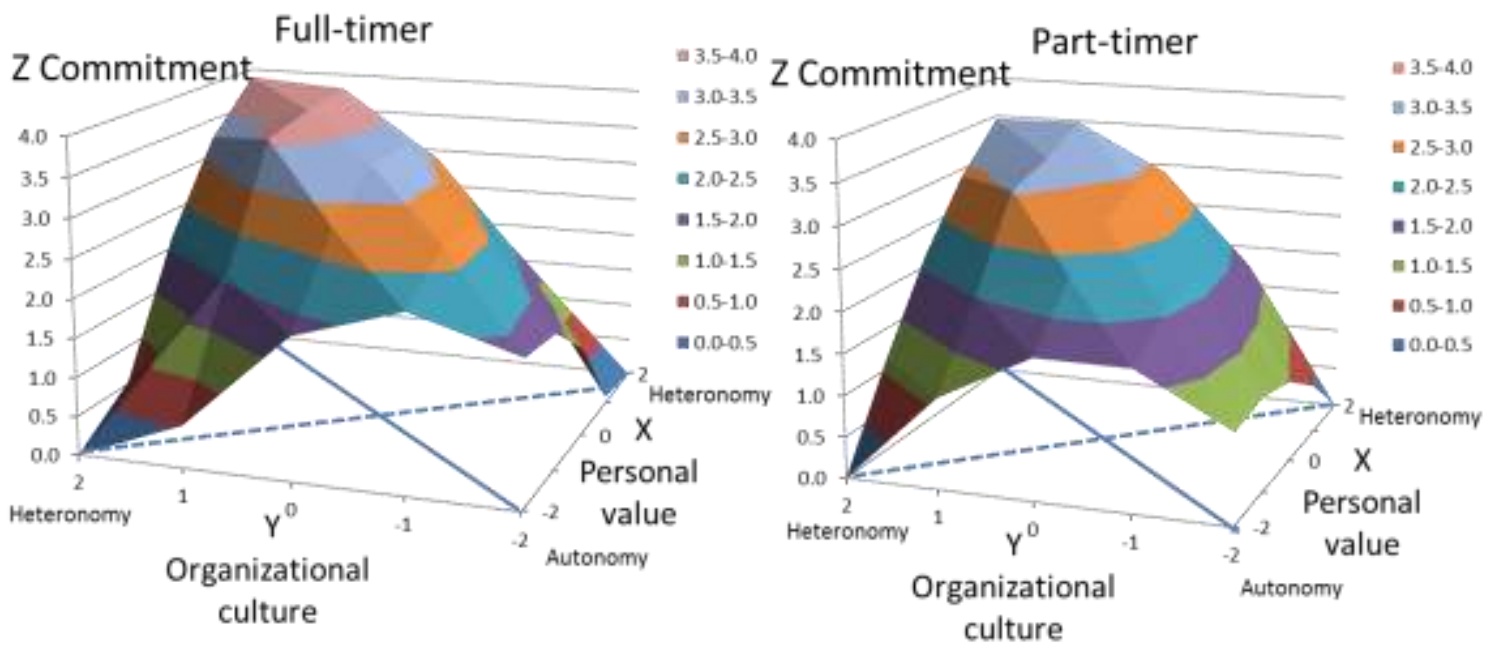

3 Summary of the results and hypothesis testing

\subsection{Hypothesis 1 concerning the effect of P-O fit and P-O unfit}

Comparison of the effect of $\mathrm{P}-\mathrm{O}$ fit and $\mathrm{P}-\mathrm{O}$ unfit on organizational commitment between fulltimers and part-timers in the case study company was performed on the comparable dimensions (human-oriented vs. task-oriented and autonomy vs. heteronomy) using polynomial regression analysis with surface response analysis.

Results concerning the comparable dimensions indicated that organizational commitment rose concomitantly with the value fit between persons and the organization regardless of the employment status. Similarly, the level of organizational commitment declined when P-O unfit of value was observed in both types of employment. Therefore, the first hypothesis that: "Organizational commitment will be higher in proportion to congruence between organizational culture and individual value. Conversely, organizational commitment will be lower in proportion to incongruence between organizational culture and individual value." was supported.

\subsection{Hypothesis $\mathbf{2}$ concerning the effect of $\mathrm{P}-\mathrm{O}$ fit depending on employment statuses}

The second Hypothesis that "the effect of $\mathrm{P}-\mathrm{O}$ fit and $\mathrm{P}-\mathrm{O}$ unfit on organizational commitment of full-timers will be larger than that of part-timers" was not supported. Although the coefficients of determination $\left(R^{2}\right)$ explaining full-timer samples were larger than those explaining part-timer samples in so far as the two dimensions of human-oriented vs. task oriented and autonomy vs. heteronomy, it was not always applicable to the other five dimensions.

However, a new hypothesis might be suggested by reviewing the verification results of the second hypothesis while focusing on the results of polynomial regressions using each dimension of humanoriented vs. task oriented and autonomy vs. heteronomy as the independent variables. 


\title{
International Conference on Research in HUMAN RESOURCE MANAGEMENT
}

\author{
March 7-9, 2019 , London-United Kingdom
}

The $\mathrm{a}_{1}$ represented the slope of the lines of perfect congruence against the Z-axis (commitment). Statistical significance was found concerning the $a_{1}$ values only in the cases of part-timers at both response surface tests relation to the two dimensions of human-oriented vs. task oriented and autonomy vs. heteronomy. In addition, the absolute values of $a_{1}$ calculating from part-timer-samples were larger in both dimensions than those from full-timer-samples. Those lead to the hypothesis that part-timers might have a tendency to enhance their organizational commitment in proportion to improving the compatibility with organizational culture in certain dimensions, and that the rate of increase of the part-timers' commitment might be larger than those of full-timers'.

Regarding $a_{3}$ representing the slope of the line of incongruence against Z-axis, the values showed around the same degree between both employment statuses in the dimension of autonomy vs. heteronomy. Regarding the human-oriented vs. task-oriented dimension, however, the absolute $a_{3}$ value of full-timers was larger than that of part-timers, and just the value of full-timers was significant at the $10 \%$ level. Additionally, on the one hand, the full-timers' convex surfaces along the lines of incongruence bulged out largely in both dimensions of human-oriented vs. task-oriented and autonomy vs. heteronomy, while on the other hand, the part-timers' corresponding convex surfaces were relatively flat and the $\mathrm{a}_{4}$ values were also relatively small and not significant in both dimensions. Based on the above considerations, full-timers might decline organizational commitment drastically, relative to part-timers when they are incongruent with their organizations.

To sum up, in the full-timers' case, the slope of perfect lines of congruence might be smaller and of lines of incongruence might be larger than those of part-timers. In contrast, in the case of parttimers, the slope of perfect lines of congruence might be larger and of lines of incongruence might be smaller than those of full-timers. In other words, the effect of P-O unfit on full-timers' organizational commitment would be larger than on part-timers', and the effect of $\mathrm{P}-\mathrm{O}$ fit on parttimers' organizational commitment would be larger than on full-timers'.

The second hypothesis was built on the premise that P-O fit and P-O unfit was regarded as being both ends of the same dimension like prevailing multiple regression analysis, and being proposed relative to a large effect of both $\mathrm{P}-\mathrm{O}$ fit and unfit on full-timers. However, it might well be said that examining the effect of P-O fit and P-O unfit separately using polynomial regression with response surface methodology found the different ways of effects instead of the simple hypothesis.

We are perhaps able to present following exploratory pair propositions that $\mathrm{P}-\mathrm{O}$ unfit should have a larger impact on job attitude of full-timers than that of part-timers, and that $\mathrm{P}-\mathrm{O}$ fit should have a larger impact on job attitude of part-timers than that of full-timers. Further investigations concerning these new hypotheses will be carried out in the discussion part.

\subsection{Hypothesis 3 concerning the effect of incongruence directions depending on employment statuses}




\title{
International Conference on Research in HUMAN RESOURCE MANAGEMENT
}

\author{
March 7-9, 2019 , London-United Kingdom
}

P-O unfit in the dimension of autonomy vs. heteronomy had the substantial negative effect on organizational commitment of all employees, both full-timers and part-timers regardless of the directions of incongruence.

However, at the human-oriented vs. task-oriented dimension, the possibility was pointed out that directions of incongruence between organizational culture and personal value should have different level of influence on organizational commitment. To put it concretely, on the occasion of full-timers, organizational commitment was lower when there was the incongruence generated by the case that the value of personal sense of human-oriented value exceeded that of human-oriented organizational culture than when the incongruence was resulting from the case that the value of human-oriented organizational culture exceeded that of personal sense of human-oriented value. Regarding part-timers, the tendency was implied that organizational commitment was lower when there was the incongruence generated by the case that the value of human-oriented organizational culture exceeded that of the value of personal sense of human-oriented value than when there was the incongruence generated from the case that the value of personal sense of human-oriented value exceeded that of human- oriented organizational culture.

Therefore, not supported was the third hypothesis: "Organizational commitment of full-timers will be lower in the case that incongruence generated from individual values fall short of corresponding organizational values (that is, organizational culture which an organization requires its members to believe) than the commitment in the case of incongruence generated from individual values differing excessively from corresponding organizational values (culture). Inversely, organizational commitment of part-timers will be lower in the case that incongruence generated from individual values deviate excessively from the corresponding organizational values (culture) than the commitment in the case of incongruence generated from individual values falling short of corresponding organizational values. In short, the organizational commitment of part-timers will be lower in the case of the value unfit from $O<P$ than the value unfit from $O>P$."

Rather, an opposite effect to the hypothesis was suggested as far as the human-oriented vs. task oriented dimension is concerned. However, the possibility of a moderating effect that the effect of directions of incongruence should have a different effect depending on the employment statuses was implied through the examination of the third hypothesis.

On the other hand, the moderating effect of employment statuses on the relationship between directions of incongruence and organizational commitment was not found in the autonomy vs. heteronomy direction.

In sum, these findings suggested that the moderating effect of employment status on the relationship between P-O unfit and organizational commitment would not always necessarily occur. One of the consistent explanations of our seemingly contradictory findings between human-oriented vs. task-oriented dimension and autonomy vs. heteronomy dimension was the hypothesis that the moderating effect of employment status on the relationship between directions of P-O incongruence 


\title{
International Conference on Research in HUMAN RESOURCE MANAGEMENT
}

\author{
March 7-9, 2019 , London-United Kingdom
}

and organizational commitment should be expected to occur, if full-timers and part-timers each had a different sub-culture. To put it still another way, the moderating effect should not apply if a company had a strong organizational culture as a whole affecting all employment statuses.

\section{Discussion}

\section{About the new hypothesis}

The use of polynomial regression analysis with response surface methodology instead of the prevailing multiple regression that employs difference of the scores between the values pertaining to the individual sense of worth and organizational culture made it possible for a pair of exploratory hypotheses to be proposed. First, it could be posited that P-O unfit influence the job attitudes of fulltimers more than the outlook of part-timers, and second, it is possible to propose that $\mathrm{P}-\mathrm{O}$ fit should exert larger impact on the job attitudes of part-timers than on the viewpoint of full-timers.

Then, how can the logic of the hypotheses be explained? Ogawa \& Osato (2011) indicated that college students used their recognized congruence with organizational climates as a decision-making standard to choose a place of employment. In the same way, full-timers who are inclined to work long term period in a company expect organizational compatibility at the time of joining, especially in Japan, where the prevailing hiring practices are oriented toward the induction of new graduates. The level of organizational commitment will be high when they the inductees start to work for an organization (Suzuki, 2002) because of the severity of employment screening compared to the vetting process set for part-timers. Given the above conditions, new recruits identify incompatibilities resulting from unmet initial expectations only after joining a company and it is at this juncture that organizational commitment declines.

On the other hand, it is likely to be after joining a company that part-timers recognize their congruence with a company because, from the beginning of employment, they enter a company expecting partial participation and shorter period of employment in comparison to full-timers. They tend to decide on their engagement by according high priority to employment conditions such as hourly payment, work times, and the number of working days rather than their suitability to organizational characteristics. Although part-timers with low expectations with regard to organizational culture are likely to lesser levels of commitment to the organization at the time of joining, they may gradually develop considerable organizational commitment after starting to work in a company.

\section{Limitations and future issues}

The present study separately compared the effect of P-O suitability and unsuitability on full-timers and on part-timers using polynomial regression with response surface analysis. 


\title{
International Conference on Research in HUMAN RESOURCE MANAGEMENT
}

\author{
March 7-9, 2019 , London-United Kingdom
}

It was found that each effect of $\mathrm{P}-\mathrm{O}$ fit and $\mathrm{P}-\mathrm{O}$ unfit had different levels of impact on the organizational commitment of employees depending on their employment situations. In addition, proposed was the moderating effect of employment status on the relationship between the directions of incongruence and levels of organizational commitment, and it was suggested that differences of employment statuses could function as moderators when there was a separate subculture for full-timers and part-timers. These considerations also imply the existence of other moderating factors such as departments and hierarchies that could represent different subcultures within the company structure. These will be developing issues generated through the use of surface response analysis.

Although these future issues were proposed by the examinations, the investigation pertained only to a case study. This study could contribute to the knowledge accumulation and to the presentation of new explorative hypotheses in the field. Nevertheless, additional examination of other companies belonging to different industries, firm sizes, or nationalities must be conducted in the future to generalize the findings of the present investigation. At such a time, it will be desirable to collectively use other attitudinal dependent variables to examine the scope of the outcomes of this study. In particular, the intention to quit will be a favorable option. Because of the cross-sectional research design, it is difficult to discriminate whether the commitment of part-timers decreased after joining the company or whether was low from the beginning of their employment. The intention to quit could be a variable that would overcome this limitation because it can only arise after a person actually joins a company.

Another limitation of this case study is that the number of full-time employed subjects was small in comparison to part-time employed subjects and the balance of obtained samples might be not adequate for an effective comparison to occur. It is desirable to secure a larger sample size to balance the corresponding groups of subjects.

The common method bias could posit another limitation of the study. The method of indirect fit was used to assess the P-O fit/unfit instead of direct fit. Although the direct fit method was easier to assess, our assessment based on the indirect fit was thought to be more objective. The evaluation of organizational culture and its relationship to the personal sense of value was performed independently. Even so, both items were answered based on the awareness of the employees and the risk of common method bias remained. As an alternative, other data sources such as managers may be utilized to assess organizational culture.

\section{Conclusion}

The present study aimed to compare the effects of P-O fit and of P-O incompatibility on the organizational commitment of full-time employees and part-time employees and to propose new hypotheses mainly with regard to the moderating effect of the employment statuses. Polynomial 


\title{
International Conference on Research in HUMAN RESOURCE MANAGEMENT
}

\author{
March 7-9, 2019 , London-United Kingdom
}

regression analysis with surface response methodology was performed using data from 129 fulltimers and 567 part-timers who work for a food retail/manufacturing company in Japan.

Two main findings resulted from this investigation. First, in terms of the human-oriented vs. taskoriented dimension of organizational culture, part-timers increased their commitment only at low levels of congruence and tended to decrease commitment at high levels of congruence. This outcome was in contrast to full-timers who held certain levels of commitment when they fit their values and organizational culture, whether at high levels or low levels of congruence. Second, P-O incompatibility predictably exerted negative effects on the commitment of both types of employees. However, the degree of the effect of incongruence-directions was different depending on the employment statuses. While full-timers decreased their commitment more seriously when the value of organizational culture exceeded individual worth, the opposite happened with part-timers, who evinced a more serious decrease when the value of individual worth exceeded that of organizational culture.

Finally, an exploratory new hypothesis was proposed: $\mathrm{P}-\mathrm{O}$ fit may relatively wield a more serious effect on part-timers than on full-timers; and $\mathrm{P}-\mathrm{O}$ unsuitability may exercise a relatively more significant impact on full-timers than on part-timers. These may be explained by the difference in the attitudes pertaining to engagement in the company. Full-timers might decide to join a company with the expectation of a value $\mathrm{P}-\mathrm{O}$ fit. As a result, the $\mathrm{P}-\mathrm{O}$ unfit acknowledged after joining if the actual experience goes against their expectations would be more infuluencial in constituting their attitudes toward the company. Conversaly, part-timers may not have such expectations concerning the $\mathrm{P}-\mathrm{O}$ value fit at the time of joining because they expect a temporary and limited work time in the company.Hence, $\mathrm{P}-\mathrm{O}$ fit that is confirmed recognized after engagement is likely to affect them much more than full-timers who might take such P-O fit for granted.

\section{Acknowledgment}

This work was supported by JSPS KAKENHI Grant Number JPS15H03379. We appreciate the employees and the director of the cooperating company for this research. Name of the company was shown anonymously considering influence on the reputation from their customers, and also appreciate Department of Commerce, Industry and Labor, Osaka Prefectural Government and the principal investigator, Mr. Hiromasa Tanaka.

\section{References}

Allen, N. J. and Meyer, J. P. (1990). "The measurement and antecedents of affective, continuance and normative commitment to the organization,"Journal of Occupational and Organizational Psychology, Vol. 63, No. 1, pp. 1-18. 


\section{International Conference on Research in HUMAN RESOURCE MANAGEMENT}

\section{March 7-9, 2019 , London- United Kingdom}

Atwater, L. E., Ostroff, C., Yammarino, F. J., \& Fleenor, J. W. (1998). "Self-other agreement: Does it really matter? ," Personnel Psychology, Vol. 51, pp. 577-598.

Edwards, J. R. (1994). "The study of congruence in organizational behavior research: Critique and proposed alternative," Organizational Behavior and Human Decision Processes, Vol. 58, pp. 51-100. Edwards, J. R. (2002). Alternatives to difference scores: Polynomial regression analysis and response surface methodology. In F. Drasgow \& N. W. Schmitt (Eds.), Advances in Measurement and Data Analysis (pp. 350-400). San Francisco: Jossey-Bass.

Forehand, G. A. and Gilmer, B. V. H. (1964). "Environmental variation in studies of organizational behavior," Psychological Bulletin, Vol. 62, No. 6, pp. 361-382.

Hoffman, B. J., and Woehr, D. J. (2005). "A quantitative review of the relationship between personorganization fit and behavioral outcomes," Journal of Vocational Behavior, Vol. 68, pp. 389-399.

Kristof, A. L. (1996). "Person-organization fit: An integrative review of its conceptualizations, measurement, and implications," Personnel Psychology, Vol. 49, No. 1, pp. 1-49.

Matsuyama, K. (2010). "Job attitudes and mental health of nonpermanent employees," Japanese Journal of Administrative Science, Vol. 23, No. 2, pp. 107-121 (in Japanese).

Miller, H. E., and Terborg, J. R. (1979).“Job attitudes of part-time and full-time employees," Journal of Applied Psychology, Vol. 64, pp. 380-386.

Mowday, R. T., Steers, R. M., and Porter, L. W. (1979). "The measurement of organizational commitment," Journal of Vocational Behavior, Vol. 14, No. 2, pp. 224-247.

Ogawa, N. and Osato, D. (2011). "Identification of criteria used by Japanese college students in selecting a potential employer using direct questioning and policy-capturing Methodology," Japanese Association of Industrial/Organizational Psychology Journal, Vol. 25, No.1, pp. 24-41. (in Japanese)

Ogawa, N. and Osato, D. (2013). Report on hiring practices of Japanese companies about new graduates, Working Paper Series, No.140, The Research Institute for Innovation Management, Hosei University (in Japanese).

Ogawa, N., Osato, D., and Tanaka, H. (2018). A diagnostic report on food manufacturing and retailing company X, Working Paper Series, No.189, The Research Institute for Innovation Management, Hosei University (in Japanese).

Ogawa, N. and Osato, D. (2018). "Comparison of the effect of person-organization fit between employment forms using surface response analysis: An exploratory study in a food retail/manufacturing company case," The Proceedings of the 21th Annual Convention of Japanese Association of Administrative Science," pp. 290-297 (in Japanese).

Ogawa, N., Takahashi, K., and Osato, D. (2014) "The empathetic sorting technique: Measuring corporate culture by sorting illustrated value statements," Business Studies Journal, Vol. 6, pp. 81101. 


\section{International Conference on Research in HUMAN RESOURCE MANAGEMENT}

March 7-9, 2019 , London- United Kingdom

Robbins S. P. and Judge, T. (2007). Essentials of Organizational Behavior (9th Edition) : NJ: Prentice Hall.

Schein, E. H. (1985). Organizational Culture and Leadership: A Dynamic View. San Francisco: JosseyBass.

Schneider, B. (1987). "People make the place," Personnel Psychology, Vol.40, pp. 437-453.

Shanock, L. R., Baran, B. E., Gentry, W. A., Pattison, S. C., and Heggestad, E. D. (2010). "Polynomial regression with response surface analysis: A powerful approach for examining moderation and overcoming limitations of difference scores," Journal of Business and Psychology, Vol. 25, No. 4, pp. 543-554.

Suzuki, R. (2002). Persons and Organizations: Transformation of Organizational Commitment and Career Development. Hakuto-Shobo Publishing Company (in Japanese).

Thorsteinson, T. J. (2003). "Job attitudes of part-time vs. ful1-time workers : A meta-analytic review," Journal of Occupational and Organizational Psychology, Vol. 76, pp. 151-177.

Verquer, M. L., Beehr, T. A., and Wagner, S. H. (2003). "A meta-analysis of relations between personorganization fit and work attitudes," Journal of Vocational Behavior, Vol. 63, pp. 473-489. 